\title{
Altered Light Interception Reduces Grape Berry Weight and Modulates Organic Acid Biosynthesis During Development
}

\author{
Seth DeBolt \\ School of Agriculture, Food and Wine, The University of Adelaide, 5005 \\ Australia; the Cooperative Research Centre for Viticulture, P.O. Box 145, \\ Glen Osmond, SA 5064 Australia, and the Department of Horticulture, N-318 \\ Agricultural Sciences North, University of Kentucky, Lexington, KY 40546- \\ 0091
}

\author{
Renata Ristic, Patrick G. Iland, and Christopher M. Ford ${ }^{\mathbf{1}}$ \\ School of Agriculture, Food and Wine, The University of Adelaide, 5005 \\ Australia; and the Cooperative Research Centre for Viticulture, P.O. Box \\ 145, Glen Osmond, SA 5064 Australia
}

Additional index words. grapevine, organic acids, light interception

\begin{abstract}
The response of grape berries at a cellular level to environmental change was explored with particular emphasis on physiological changes such as weight, sugar content, and the biosynthesis of organic acids. Three levels of light were used: highly exposed, moderately exposed, and light-excluding boxes $(1 \%$ ambient with no change in temperature effect). Berry weight was significantly lower in light-excluding boxes than in exposed bunch treatments. Organic acid content and berry development were followed throughout the growing season. Light exclusion resulted in a significant reduction of both tartaric acid and oxalic acid compared with highly exposed fruit, suggesting that in this experiment, light irradiance influenced accumulation of these metabolites. In contrast, malic acid was broken down postveraison at a dramatically slower rate in light exclusion treatments. The sink properties of grape berries appear to change according to the light received by the bunch. These data imply that cluster shading significantly reduced berry size and suggest the role of organic acids as osmotica.
\end{abstract}

Environmental conditions play a significant role in regulating both primary and secondary metabolism during fruit ripening. In grapevines, the effect of light exposure on grape quality is of particular importance because it can be modulated using a wide range of practices, including trellising, leaf removal, and pruning strategies, each designed to affect in some way the amount of light intercepted by each bunch and thereby promote desirable outcomes in the harvested crop. A direct link between light exposure and organic acid biosynthesis by both immature and mature berries has been reported (DeBolt et al., 2006, 2007; Kliewer and

\footnotetext{
Received for publication 8 Nov. 2007. Accepted for publication $6 \mathrm{Jan} .2008$.

This project was supported by the Australian Government's Cooperative Research Centre Program and conducted by the Cooperative Research Centre for Viticulture.

We thank Brad Greatrix for technical assistance. Bruce Brooks of the South Australian Bureau of Meteorology is thanked for the provision of weather station data. We also thank Steve Tyerman, Matt Hayes, and Vanessa Melino for critical comments.

${ }^{1}$ To whom reprint requests should be addressed; e-mail christopher.ford@adelaide.edu.au
}

as warm (Smart and Dry, 2004) with mean January temperature in the range from 21.0 to $22.9^{\circ} \mathrm{C}$ and 1817 biologically effective day degrees (Gladstones, 1992). Rainfall is moderate $(506 \mathrm{~mm})$ with high summer evaporation and low relative humidity. The soil of the site is classified as a light pass fine sandy loam (Northcote, 1988).

The vines used in the experiment were 'Shiraz', clone BVRC 12. The trellis system was a single-wire system, cordon-trained and spur-pruned. Row and vine spacing were $3.0 \mathrm{~m}$ and $2.25 \mathrm{~m}$, respectively, with the rows orientated in an east-west direction. Vineyard management practices were similar to district practices. All treated vines received irrigation of $1 \mathrm{ML} \cdot \mathrm{ha}^{-1}$ from the same water source with fixed undervine drippers. The irrigation was two times higher than the district average, but this level of irrigation was necessary to produce vigorous shoot growth, which could be manipulated to obtain various degrees of sunlight intensity at the bunch zone. There was no Botrytis or powdery mildew infection in the experimental vines; routine control measures were taken in accordance with standard practices.

The experimental design consisted of three treatments that altered bunch exposure to sunlight to achieve shaded bunches, moderately exposed bunches, and highly exposed bunches. The treatments were:

Moderately exposed treatment ["control" (MET)]: no canopy manipulation was undertaken to obtain moderate exposure of bunches to sunlight.

Highly exposed treatment (HET): high posts $(2.5 \mathrm{~m})$ were placed on the ends of panels with the addition of three rows of foliage wires $50 \mathrm{~cm}$ apart. Vine canopies were (vertically) divided and shoots were trained upward and downward. Vertical positioning of shoots, and, when required for HET, leaf removal around bunches, were carried out periodically during the season to maintain maximum levels of bunch exposure to light appropriate for this treatment.

Box treatment (BT): bunches in a zone of highly exposed bunches were enclosed in boxes (Downey et al., 2004). The boxes were made from white polypropylene sheeting $(0.6 \mathrm{~mm})$ painted black on the inside. They were $\approx 250 \mathrm{~mm}$ in length and $120 \mathrm{~mm}$ deep with the front of the box 150 $\mathrm{mm}$ wide and the back $210 \mathrm{~mm}$ wide. The boxes were designed to eliminate sunlight (greater than $99.5 \%$ of ambient) while allowing airflow around bunches without creating any temperature difference between bunches inside the boxes and those in the canopy (Downey et al., 2004). Bunches were enclosed in boxes after fruit set.

\section{Materials and Methods}

The vineyard site selected for this study was at Nuriootpa (lat. $34^{\circ} 29^{\prime} \mathrm{S}$, long. $139^{\circ} 01^{\prime} \mathrm{E}$ ), in the Barossa Valley district of South Australia, $\approx 80 \mathrm{~km}$ northeast of Adelaide. The climate of the region is described
The treatments were arranged in a randomized block design along one row of vines. There were eight replicates of each treatment, each replicate consisting of a panel of three vines. The experiment was conducted in the 2000 to 2001 season. 
Sunlight intensity at the bunch zone was determined on a cloudless day between 12 PM and 1 PM using a septometer (Decagon Devices, Cambridge, UK). Approximately 4 weeks before harvest, readings were made at the fruit zone on both sides of the each vine with the septometer positioned parallel to the cordon and pointed upward. Ambient measures were taken by positioning the septometer at the bunch zone height outside the canopy.

Samples were collected at regular intervals during berry development starting when berries were $\approx 3$ to $4 \mathrm{~mm}$ in diameter corresponding to Eichorn and Lorenz (E-L) growth stage 29 (Coombe, 1995) and finishing when berries reached a maturity of 26 to $27{ }^{\circ}$ Brix corresponding to E-L growth stage 38. Sampling began $28 \mathrm{~d}$ after flowering (DAF) on 12 Dec. 2000 and finished on 4 Mar. 2001 (110 DAF). On each sampling date, three randomly selected bunches from each of the eight replicates of MET and HET and one bunch from each of the eight replicates of the BT treatment were collected. For each treatment replicate, all the berries from bunches were combined and then randomly divided into three subsamples of 50,30 , and 30 berries. Berries were frozen at $-20^{\circ} \mathrm{C}$ until required for analysis. Berry weights were determined from the 50-berry samples, which were subsequently crushed and used for the determination of total soluble solids (TSS expressed as ${ }^{\circ}$ Brix) by refractometry. The organic acid extraction protocol used was described previously (DeBolt et al., 2004) using weighed five-berry subsamples prepared from each sample of frozen berries (three replicates per sampling date per treatment; see "Results and Discussion"). Highperformance liquid chromatography (HPLC) separation of tartaric, malic, and oxalic acids was achieved using a Prevail Organic Acid column $250 \times 4.6 \mathrm{~mm}, 5-\mu \mathrm{m}$ (Alltech Associates, Deerfield, IL); the mobile phase was $25 \mathrm{mM} \mathrm{KH}_{2} \mathrm{PO}_{4}$ adjusted to $\mathrm{pH} 2$ with phosphoric acid at a flow rate of $0.5 \mathrm{~mL} /$ min. Sample volumes of $10 \mu \mathrm{L}$ were loaded through an autosampler (model 507e; Beckman System Gold, Beckman Coulter, Fullerton, CA). For HPLC quantitation of oxalic acid, which coeluted with fructose from the $250 \times 4.6-\mathrm{mm}$ Prevail column (data not shown), two alternative chromatographic approaches were used. A $100 \times 2 \mathrm{~mm} \mathrm{3- \mu m}$ Prevail organic acid column, with mobile phase as described previously and a flow rate of $0.2 \mathrm{~mL} / \mathrm{min}$, permitted determination of oxalic acid without interference from coeluting compounds. Additionally, a Rezex organic acid column, $300 \times 7.6 \mathrm{~mm}$ (Phenomenex, Torrance, $\mathrm{CA}$ ), was used with 2.5 mM sulfuric acid as the mobile phase and a flow rate of $0.5 \mathrm{~mL} / \mathrm{min}$. Detection of the organic acids, including oxalic acid, tartaric acid, and malic acid, was by ultraviolet absorbance $(210 \mathrm{~nm})$ with a diode array detector to assess the spectral quality of elution products (model 168; Beckman System Gold). Organic acid quantitation was achieved using standard curves obtained from authentic compounds (data not shown).
All data are reported as the mean of the three observations.

Data were analyzed for statistical variability and graphed using Genstat ${ }^{\circledR}$ release 10 (VSN International, Hemel Hempstead, UK), Microsoft Excel (Redmond, WA), and Prism 5 software GraphPad Software (San Diego, CA).

\section{Results and Discussion}

Degree of sunlight intensity at the bunch zone. Light reaching the developing bunch has long been a factor that viticulturists have sought to control, primarily for consequences associated with temperature fluctuations arising from increased or decreased light exposure (Gladstones, 1992). Smart (1987) suggested that the effects of light on plant growth and development are manifest in three ways: by thermal, phytochrome-mediated, and photosynthetic processes. In the present work, we sought to eliminate differences resulting from temperature by the use of shading boxes shown previously to produce no increase in temperature of bunches compared with bunches with no shading (Downey et al., 2004; C. M. Ford, unpub. data). The degree of sunlight intensity at the bunch zone differed significantly $(P<0.001)$ between treatments. Measures of light intensity (photosynthetically active radiation) at the bunch zone showed that the fruit of BT received less than $1 \%$ of available light. The light intensity at the bunch zone was $10 \%$ to $40 \%$ of ambient [ 300 to 700 photosynthetically active phon flux density (PPFD)] for MET and $40 \%$ to $80 \%$ of ambient (800 to 157 1500 PPFD) for HET (data not shown).

Berry developmental profiles indicate that light interference reduces berry weight. Berry weights and the accumulation of total
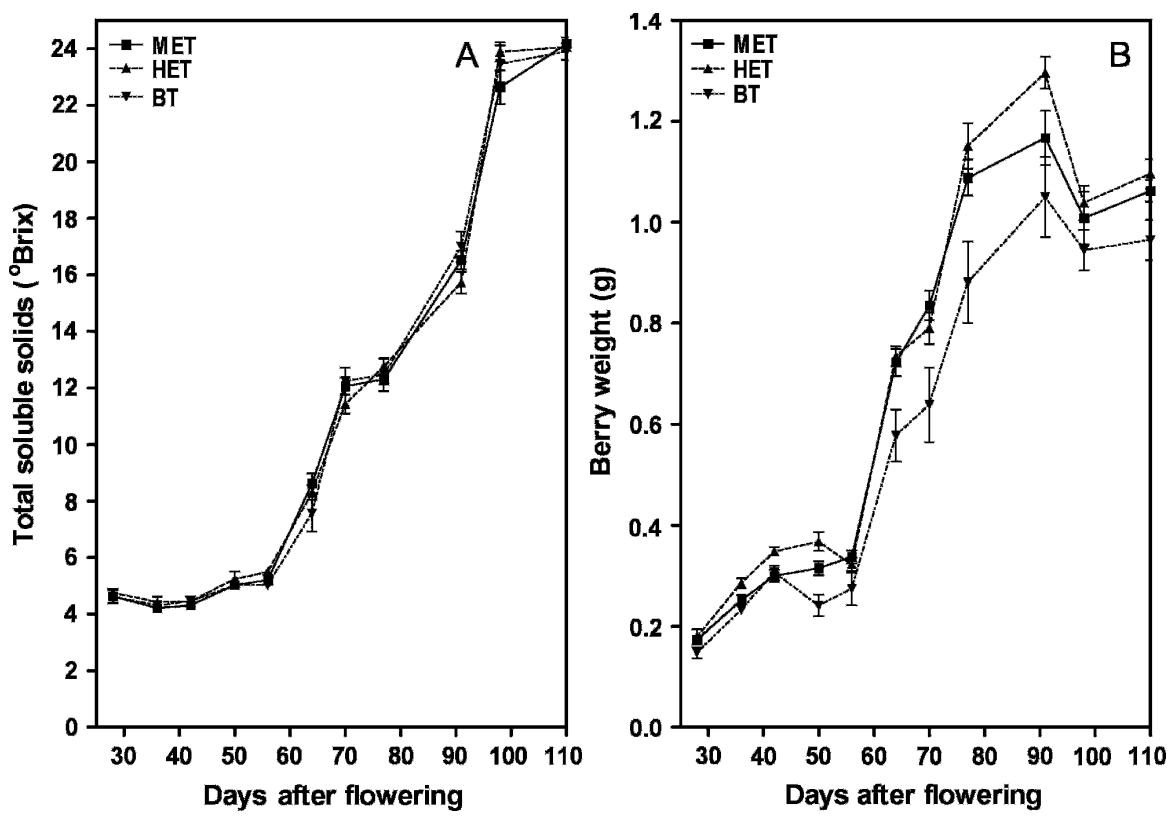

Fig. 1. Developmental data for berries of grapevine cultivar 'Shiraz' grown under three light regimes. (A) Total soluble solids. (B) Berry weight. HET = highly exposed treatment; $\mathrm{MET}=$ moderately exposed treatment; $\mathrm{BT}=$ box treatment. The mean and SE values are shown $(\mathrm{n}=8)$. soluble sugars were measured for all samples from the eight replicates per treatment taken in the 2000 to 2001 growing season throughout development. This level of replication was used because previous investigations had indicated to us that season-on-season repetition of the treatments applied to the vines caused physiological stresses resulting in excessive variation within treatments, potentially capable of masking any between-treatment effects (data not shown). Berry weights were comparable for MET and HET but were significantly less for BT at all stages of development (Wilcoxon signed rank test, $P<0.001$; Fig. 1A). TSS data were comparable across all treatments (Fig. 1B). Veraison (the onset of berry softening and sugar accumulation) occurred between 60 and 70 DAF for all treatments. The reduction in berry weight resulting from reduced cluster exposure to light was not expected. Several plausible scenarios could explain this result. One possibility is that a reduction in photosynthetic activity may be responsible for the effect. During the early stages of berry development, green berries possess a capacity for photosynthetic activity (Peynaud and Riberereau-Gayon, 1971) so any interference in the amount of light reaching the berry will thus result in reduced photosynthesis. As berries progress through veraison, their photosynthetic capacity is lost and the subsequent events of berry expansion and sugar accumulation are driven by the import of sucrose from leaves and remobilization of reserves stored in the wood (reviewed in Coombe, 1992). Berry weights for BT did not attain the levels of the MET or HET postveraison, suggesting that the early limitation in growth was not reversed by later import of sugars. Conversely, TSS data showed that relative rates of sugar accumulation were 
comparable in all treatments. A second explanation may lie in the possibility that light could affect gibberellic acid (GA) biosynthesis. Experimental evidence in seedless grapevines showed that exogenous GA application during preveraison berry development increased berry size and weight (Dass and Randhawa, 1968). Moreover, light regulates expression of GA biosynthetic enzymes (Achard et al., 2007; Richards et al., 2001).

Modulating light impacts on the accumulation of grape berry organic acids. Berries grown under the three treatments were sampled throughout development and assayed for tartaric acid (TA) by HPLC (Fig. 2). For organic acid extraction, three of the eight replicates taken at each sampling date were used. The data showed a consistent, inverse relationship between TA accumulation (expressed as milligrams TA per berry) and bunch shading $(P<0.001)$. Berries from bunches grown in full shade conditions (BT) accumulated significantly less TA than both sun-exposed (HET) and moderately exposed (MET) treatments throughout berry development consistent with the studies of Kliewer (1977) and in contrast with Weaver and McCune (1960) and Crippen and Morrison (1986). All treatments showed an unexpected increase in TA per berry beginning at $\approx 60$ to $70 \mathrm{~d}$ after flowering, which was, however, not significantly different between the treatments. Meteorological records for the region indicate that a spell of extremely hot weather occurred between 10 and 24 Jan. 2001 with daytime maxima exceeding $40{ }^{\circ} \mathrm{C}$ on $5 \mathrm{~d}$, which may have contributed to a localized change in TA levels.

Malic acid (MA) levels showed no response to light intensity during the first 6 weeks of development (Fig. 3). Beyond this time, there were marked differences between treatments with a greater rate of MA accumulation per berry for MET and HET than for the fully shaded BT berries occurring up to 50 to $60 \mathrm{~d}$ postflowering. Treatments in which bunch exposure was highest, HET and MET, were marked by $\approx 3.5$-fold greater increases in the levels of MA per berry than the increase seen for BT berries. Malic acid levels in all treatments peaked $\approx 10 \mathrm{~d}$ before veraison. After the peak in MA accumulation, a general trend toward increased MA loss was observed in all treatments. Early season high levels of MA were followed postveraison by a decline to $\approx 1 \mathrm{mg}$ MA per berry at final sampling in agreement with previously published reports (Iland and Coombe, 1988; Ruffner, 1982; Terrier and Romieu, 2001). During the latter stages of development (70 d after flowering and onward), MA levels remained significantly higher in BT than either MET or HET. This suggests that at $1 \%$ ambient light with no apparent temperature effect, final MA levels were nearly $60 \%$ greater than levels for MET and HET berries, which may be indicative of light activation of metabolic enzymes (Famiani et al., 2000).

Oxalic acid (OA) accumulation in the developing grape during the period of TA

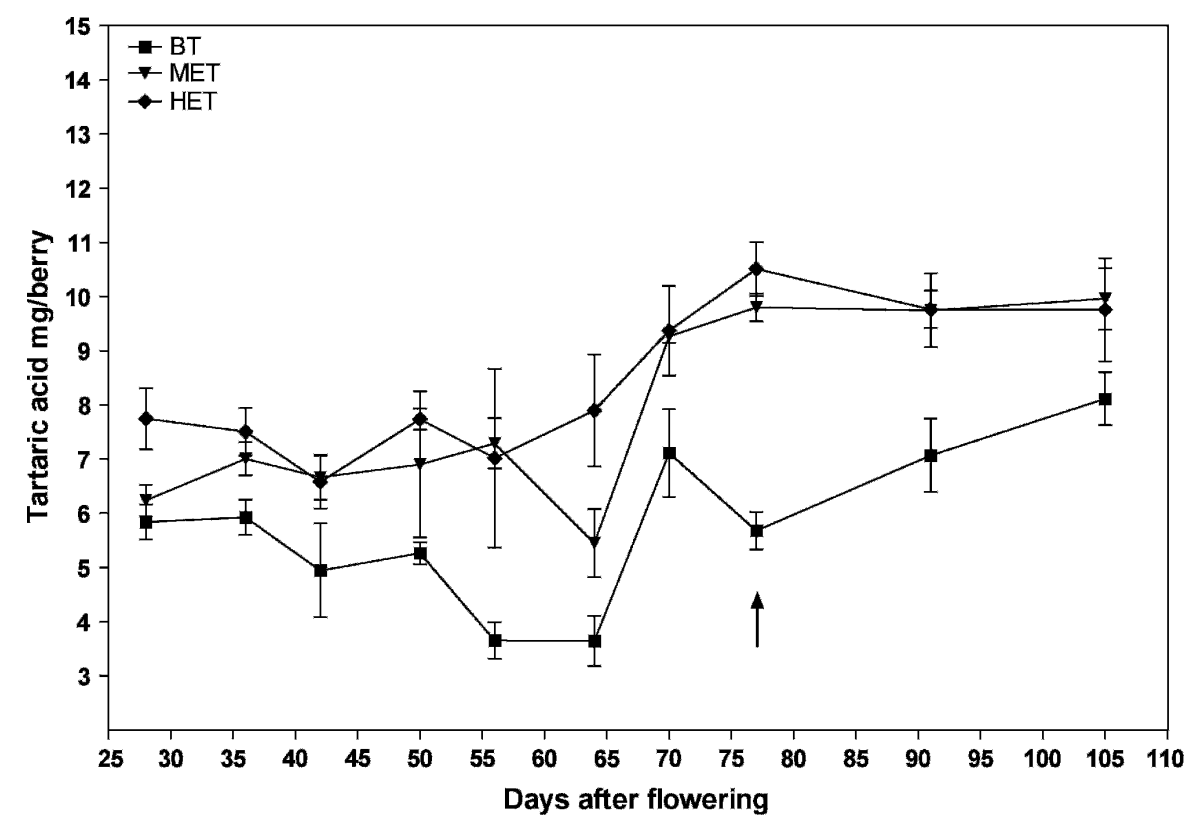

Fig. 2. Tartaric acid profiles throughout development of 'Shiraz' berries under three light regimes. Tartaric acid levels expressed as milligrams acid per berry. HET = highly exposed treatment; MET = moderately exposed treatment; BT $=$ box treatment. The mean and SE values are shown $(n=3)$; the vertical arrow at $77 \mathrm{~d}$ after flowering indicates veraison.

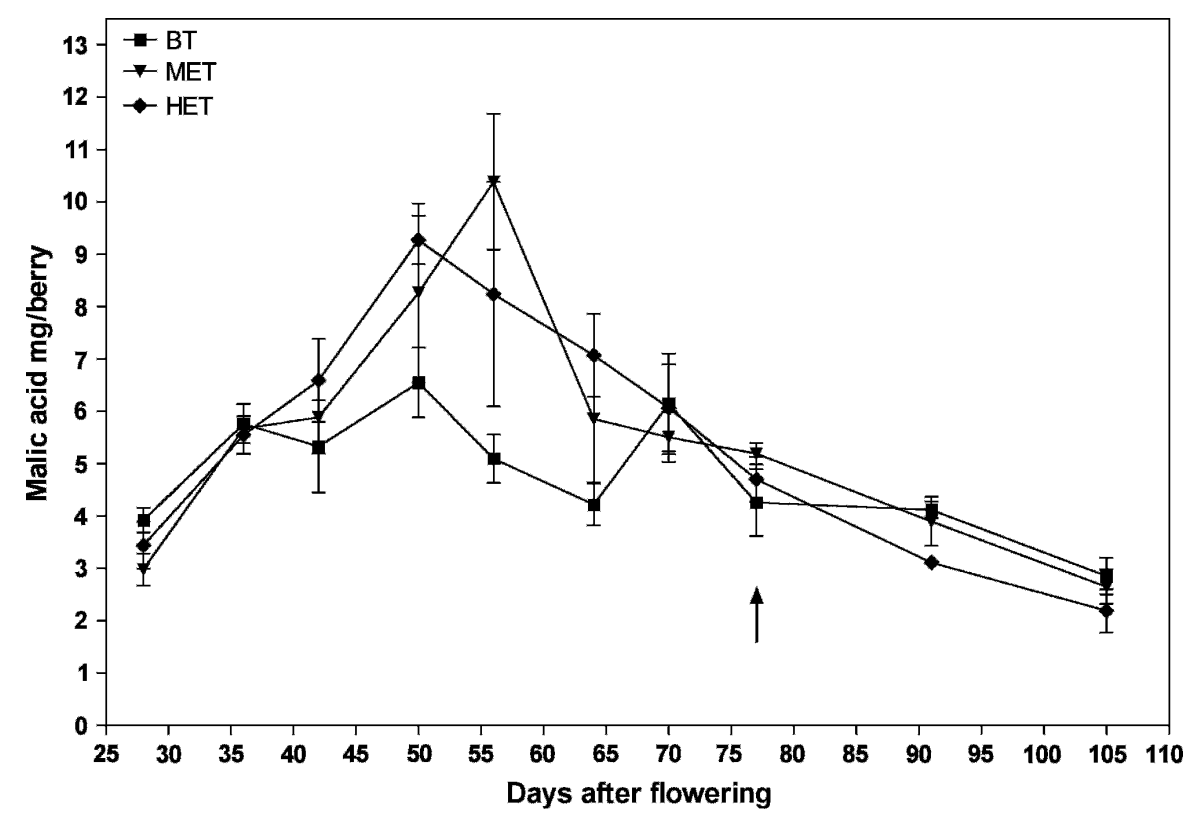

Fig. 3. Malic acid profiles throughout development of 'Shiraz' berries under three light regimes. Malic acid levels expressed as milligrams acid per berry. HET $=$ highly exposed treatment; MET = moderately exposed treatment; BT = box treatment. The mean and SE values are shown $(n=3)$; the vertical arrow at $77 \mathrm{~d}$ after flowering indicates veraison.

synthesis was determined after the extraction of berries sampled under acidic conditions and is a measurement of the oxalic acid sequestered in calcium oxalate crystals (DeBolt et al., 2004). OA occurred throughout development of the berry and was present from the earliest sampling (Fig. 4). Increased OA accumulation was seen with increased light exposure throughout the sampling period $(P<0.001)$. In BT berries, the profile of OA accumulation followed that for HET berries, but levels in BT berries were between
$40 \%$ and $70 \%$ of those in HET at each sampling point. Levels of OA in MET berries were intermediate between the BT and HET data, with the exception of the 42 DAF samples, in which OA values dropped below the level seen in BT (Fig. 4). A maximum level of OA per berry was seen at 42 DAF in both BT and HET with levels three to four times higher at this point than at the first sampling (28 DAF). Peak OA levels per berry occurred at 36 DAF in MET at an sixfold higher level than observed at 28 DAF. OA 
levels decreased in BT and HET in the period 42 to 50 DAF. In MET, OA levels per berry remained constant over the period 42 to 56 DAF. At the final sampling point for which OA was analyzed, 56 DAF, BT and control (MET) berries contained approximately equal

One of the original aims of this study was to further understand the flux between L-ascorbic acid (ASC) and its degradation products, TA and OA, which in the grape berry occurs through distinct pathways (DeBolt et al., 2004). Recent research (Dowdle et al., 2007) highlighted the light-responsiveness of key genes in the GDP-mannose pathway of ascorbate synthesis. The site of synthesis of the ascorbate from which TA and $\mathrm{OA}$ are formed in grapevines remains unknown; nevertheless, it is tempting to speculate that gross alterations to the light regime during berry development, as exemplified in the box shading and high-light treatments reported here, may result in sigbate reflected in changes in the levels of the amounts of OA (Fig. 4). nificant changes to the metabolism of ascor-

catabolic products OA and TA. In common with TA, reduced OA levels per berry were associated with increased bunch shading. Comparing levels of OA and TA accumulation on a molar basis over the period of early berry development (to 56 DAF) (Table 1) suggested that overall, $\approx 10$-fold greater diversion of ASC was occurring into TA than to OA. Our previous data, obtained using radiolabeled ASC in feeding experiments, indicated that $\approx 20 \%$ of labeled ASC taken up through the bunch rachis was recovered in crystals of calcium oxalate, whereas $\approx 50 \%$ was recovered as tartaric acid (DeBolt et al., 2004). This suggests a somewhat different ratio of ASC utilization into OA than observed here, most probably associated with the use of grapes sampled at only one developmental stage in the earlier work.

Despite exhaustive efforts, using a range of chemical and enzymatic treatments of the frozen berries and their extracts, we were unable to determine ASC levels in the berries used for these experiments. Liquid chromatography-mass spectroscopy data acquired

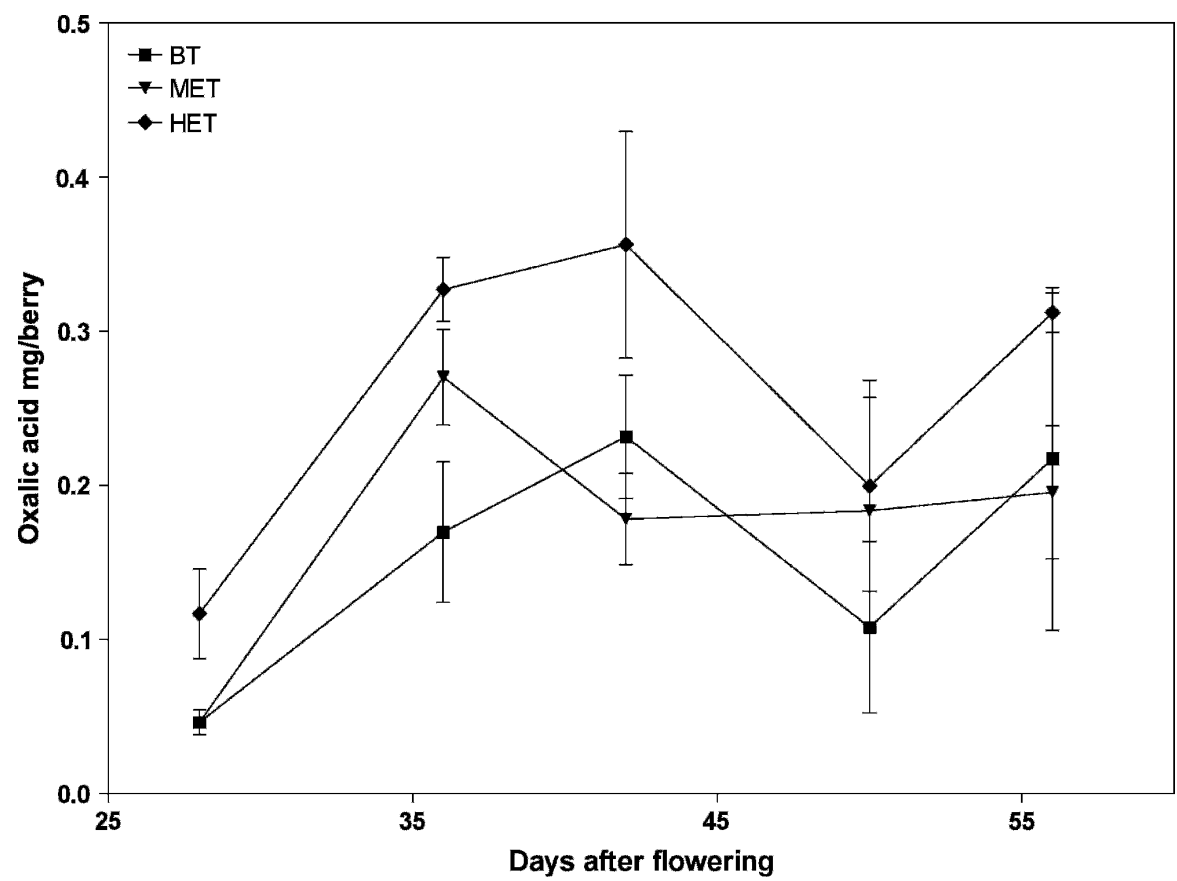

Fig. 4. Oxalic acid profiles during development of 'Shiraz' berries under three light regimes during the first $55 \mathrm{~d}$ of berry development measured by ion exclusion chromatography, expressed as milligrams acid per berry. HET $=$ highly exposed treatment; MET $=$ moderately exposed treatment; $\mathrm{BT}=$ box treatment. The mean and SE values are shown $(n=3)$.

Table 1. Levels of tartaric (TA) and oxalic (OA) acids in grape berries subjected to light exposure treatments. $^{z}$

\begin{tabular}{|c|c|c|c|c|c|c|}
\hline \multirow[b]{2}{*}{ DAF } & \multicolumn{2}{|c|}{ Box treatment } & \multicolumn{2}{|c|}{$\begin{array}{c}\text { Moderately exposed } \\
\text { treatment }\end{array}$} & \multicolumn{2}{|c|}{$\begin{array}{l}\text { Highly exposed } \\
\text { treatment }\end{array}$} \\
\hline & $\mathrm{OA}$ & TA & $\overline{\mathrm{OA}}$ & $\overline{\mathrm{TA}}$ & $\overline{\mathrm{OA}}$ & TA \\
\hline 28 & 4.6 & 38.6 & 3.1 & 41.8 & 4.3 & 55.0 \\
\hline 36 & 5.9 & 38.5 & 6.2 & 48.5 & 6.8 & 51.5 \\
\hline 42 & 6.8 & 36.0 & 6.3 & 43.7 & 5.7 & 41.7 \\
\hline 50 & 10.4 & 34.3 & 4.7 & 34.8 & 6.3 & 50.5 \\
\hline 56 & 10.8 & 54.6 & 8.3 & 61.3 & 9.5 & 86.5 \\
\hline
\end{tabular}

${ }^{2}$ All data represent $\mu \mathrm{mol}$ per berry amounts.

$\mathrm{DAF}=$ days after flowering. using protocols developed for the successful detection of ASC in other plants (Muckenschnabel et al., 2001) failed to indicate the presence of ASC or its oxidized forms in representative extracts analyzed under conditions in which authentic standards provided $\mathrm{m} / \mathrm{z}$ peaks of 177 in the positive ion mode (data not shown).

\section{Conclusion}

Light exclusion to individual berry clusters resulted in reduced berry size as well as significant modulation of TA and OA levels throughout development, suggesting that the sink properties of berries change according to the amount of light received by the bunch. Berry size and weight will depend, inter alia, on the amount of water imported, determined by the osmotic potential of the berry. Data implying that levels of organic acids vary according to berry weight therefore suggest a possible role for organic acids, in particular the otherwise metabolically inert TA, as osmotica. This hypothesis remains to be tested in future investigations. The $20.5 \%$ reduction in berry weight observed in response to shading may be explained as part of a photosynthetic effect or a reduction in GA biosynthesis, which has previously been shown to modulate berry size (Dass and Randhawa, 1968).

\section{Literature Cited}

Achard, P., L. Liao, C. Jiang, T. Desnos, J. Bartlett, X. Fu, and N.P. Harberd. 2007. DELLAs contribute to plant photomorphogenesis. Plant Physiol. 147:1163-1172.

Coombe, B.G. 1992. Research on development and ripening of the grape berry. Amer. J. Enol. Viticult. 43:101-110.

Coombe, B.G. 1995. Adoption of a system for identifying grapevine growth stages. Aust. J. Grape Wine Res. 1:104-110.

Crippen, D.D., Jr., and J.C. Morrison. 1986. The effects of sun exposure on the compositional development of Cabernet Sauvignon berries. Amer. J. Enol. Viticult. 37:235-242.

Dass, H.C. and G.S. Randhawa. 1968. Response of certain seeded vitis vinifera varieties to gibberellin application at postbloom stage. Amer. J. Enol. Viticult. 19:52-55.

DeBolt, S., D.R. Cook, and C.M. Ford. 2006. Ltartaric acid synthesis from vitamin $\mathrm{C}$ in higher plants. Proc. Natl. Acad. Sci. USA 103:56085613.

DeBolt, S., J. Hardie, S. Tyerman, and C.M. Ford. 2004. Composition and synthesis of raphide crystals and druse crystals in berries of Vitis vinifera L. cv. Cabernet Sauvignon: Ascorbic acid as precursor for both oxalic and tartaric acids as revealed by radiolabelling studies. Aust. J. Grape Wine Res. 10:134-142.

DeBolt, S., V.J. Melino, and C.M. Ford. 2007. Ascorbate as a biosynthetic precursor in plants. Ann. Bot. (Lond.) 99:3-9.

Dowdle, J., T. Ishikawa, S. Gatzek, S. Rolinsli, and N. Smirnoff. 2007. Two genes in Arabidopsis thaliana encoding GDP-L-galactose phosphorylase are required for ascorbate biosynthesis and seedling viability. Plant J. 52:673-689.

Downey, M.O., J.S. Harvey, and S.P. Robinson. 2004. The effect of bunch shading on berry development and flavonoid accumulation in 
Shiraz grapes. Aust. J. Grape Wine Res. 10:5573.

Famiani, F., R.P. Walker, L. Tecsi, Z.H. Chen, J. Proietti, and R.C. Leegood. 2000. An immunohistochemical study of the compartmentation of metabolism during the development of grape (Vitis vinifera L.) berries. J. Ex. Bot. 51:675683.

Gladstones, J. 1992. Viticulture and environment. Winetitles, Adelaide, Australia.

Iland, P.G. and B.G. Coombe. 1988. Malate, tartrate, potassium, and sodium in flesh and skin of Shiraz grapes during ripening: Concentration and compartmentation. Amer. J. Enol. Viticult. 39:71-76.

Kliewer, W.M. 1977. Influence of temperature, solar radiation and nitrogen on coloration and composition of emperor grapes. Amer. J. Enol. Viticult. 28:96-103.

Kliewer, W.M. and H.B. Schultz. 1964. Influence of environment on metabolism of organic acids and carbohydrates in Vitis vinifera. II. Light. Amer. J. Enol. Viticult. 15:119-129.

Muckenschnabel, I., B. Williamson, B.A. Goodman, G.D. Lyon, D. Stewart, and N. Deighton. 2001. Markers for oxidative stress associated with soft rots in French beans (Phaseolus vulgaris) infected by Botrytis cinerea. Planta 212:376-381.

Northcote, K.H. 1988. Soils and Australian viticulture, p. 61-90. In: Coombe, B.G. and P.R. Dry (eds.). Viticulture volume 1: Resources. Australian Industrial Publishers, Adelaide, Australia.

Peynaud, E. and P. Riberereau-Gayon. 1971. The grape, p. 171-205. In: Hulme, A.C. (ed.). The biochemistry of fruits and their products. Academic Press, London, UK.

Richards, D.E., K.E. King, T. Ait-ali, and N.P. Harberd. 2001. How gibberellin regulates plant growth and development: A molecular genetic analysis of gibberellin signaling. Annu.
Rev. Plant Physiol. Plant Mol. Biol. 52:6788.

Ruffner, H.P. 1982. Metabolism of tartaric and malic acids in vitis: A review-Part B. Vitis 21:346-358.

Smart, R.E. 1987. Influence of light on composition and quality of grapes. Acta Hort. 206:3743.

Smart, R.E. and P.R. Dry. 2004. Vineyard site selection, p. 196-209. In: Dry, P.R. and B.G. Coombe (eds.). Viticulture volume 1-Resources. 2nd ed. Winetitles, Adelaide, Australia.

Terrier, N. and C. Romieu. 2001. Grape berry acidity, p. 35-57. In: Roubelakis-Angelakis, K.A. (ed.). Molecular biology and biotechnology of the grapevine. Kluwer Academic Publishers, Dordrecht, The Netherlands.

Weaver, R.J. and S.B. McCune. 1960. Influence of light on color development in Vitis vinifera grapes. Amer. J. Enol. Viticult. 11:179184. 